\title{
Frederick Starr Por el SUR de MÉXICO
}

\author{
Marco Antonio Calderón-Mólgora
}

\section{Introducción}

$\mathrm{F}$ rederick Starr, o "Federico Estrella", nació el 2 de septiembre de 1858 en Auburn, estado de Nueva York, y murió en Tokio, Japón, el 14 de agosto de 1933. Fue un formidable viajero; visitó varias partes del mundo como el Congo, Corea y Filipinas. Estuvo en México en más de 20 ocasiones. Como resultado de sus constantes viajes escribió varios libros y artículos. Uno de ellos lleva por título The Physcial Characters of the Indians of the Southern Mexico, publicado en 1902 por la Universidad de Chicago. Otro libro derivado de esas experiencias es un relato de sus viajes titulado In Indian Mexico, publicado en inglés en el año 1908, texto donde relata muchas de las peripecias y dificultades que debió enfrentar para obtener la información que le interesaba (Starr, 1908). Existe una versión en español de ese texto publicada por el Consejo Nacional para la Cultura y las Artes bajo el título En el México indio, traducido por Gloria Benuzillo Revah y con prólogo de Beatriz Scharrer Tamm (Starr, 1995). En 1914, en plena

Marco Antonio Calderón Mólgora, El Colegio de Michoacán. Temas de especilaización: ritual político, ceremonias cívicas y transición, cultura política. Correo lectrónico: marcoslike@gmail.com.
Revolución mexicana, publicó un grueso volumen sobre la relación entre México y los Estados Unidos, un trabajo de "historia cultural" basado en fuentes secundarias a la manera en que Starr la entendía. El antropólogo buscaba hacer comprensible la historia de México a políticos e intelectuales norteamericanos interesados en este país.

El archivo de Frederick Starr, ubicado en la colección especial de la biblioteca Regenstein de la Universidad de Chicago, contiene muchas libretas de campo así como diversas cartas y notas vinculadas a sus intereses de investigación y a sus viajes. El amplio acervo incluye varios documentos que ilustran el apoyo que Starr recibió por parte de distintas autoridades mexicanas para llevar a cabo sus investigaciones en el país. Se trata de un tema importante de la historia de la antropología dado que refleja el contexto social y político en el que se produce - o por lo menos se intenta producirconocimiento científico en una etapa de crecimiento y consolidación del imperialismo norteamericano y de cambios importantes en el Estado, tanto en México como en los Estados Unidos.

Recibido: 01 de agosto de 2012 


\section{Federick Starr, antropólogo finisecular}

La figura de Frederick Starr es controvertida y contradictoria. Fue hijo de un ministro presbiteriano y estudió en el College Lafayett, en Easton, Pensilvania, donde obtuvo el grado de doctor en el año 1885. Su formación inicial fue en ciencias naturales y durante los primeros años de su carrera académica mantuvo un estrecho vínculo con las teorías evolucionistas. Enseñó biología en el Coe College (1883-1887), en el estado de Iowa. En ese periodo mostró interés por el estudio de los indígenas iowa e incluyó literatura sobre sus costumbres en las temáticas que impartía como profesor (Stocking, 1979). También enseñó geografía en la Universidad de Chautauqua (1888-1889) y trabajó además un par de años (1889-1891) en el Departamento de Etnología del Museo de Historia Natural de Nueva York arreglando y clasificando colecciones. En 1891 pasó a ser profesor de geología y antropología en el College de Pomana, California (Dictionary of American Biography, 1935: 532). Como integrante del equipo de investigación de Franz Boas durante la exposición mundial de 1892 de Chicago, llevó a cabo estudios de antropología física entre los chéroqui. En relación con dicha feria publicó un artículo sobre antropología en el que, siguiendo a Lambroso, vincula el "comportamiento criminal y la moralidad con la evolución de la mente salvaje" (Starr, 1893: 621; Baker, 1998: 58). Ese mismo año formó parte del grupo fundador de la Universidad de Chicago encabezado por William Harper, quien le encomendó la tarea de crear y organizar, junto con Albion Small, un área de ciencias sociales o sociología (Stocking, 1979: 13). En esa etapa de su vida estaba muy interesado en la antropología física y en la historia natural.

Entre 1899 y 1901, Frederick Starr publicó varios trabajos, algunos de carácter científico y otros de divulgación. El primero trató sobre los indios de América, un libro escrito para niños norteamericanos (Starr, 1899a); publicó además un catálogo de una colección de folklore mexicano (Starr, 1899b). En 1900, en una edición de autor, aparece Notes upon the Ethnography of Southern Mexico, un documento que ofrece mucha de la información que fue recolectando poco a poco durante sus viajes al país. Un año más tarde, Starr publicó Some First Steps in Human Progress, un libro que compila muchas de las clases que preparó para la audiencia Chautauqua. A su juicio, la antropología, siguiendo al naturalista francés Jean Louis de Quatrefages, era una "historia natural del hombre." Starr creía que era posible estudiar "al hombre" como los botánicos estudiaban las plantas y los zoólogos, los animales. "En su sentido más amplio", afirma Starr, la antropología "incluye el estudio del hombre físico, así como su naturaleza mental, social y religiosa." Por eso, el conocimiento antropológico estaba necesariamente asociado a otras disciplinas como la somatología, la antropología física, la etnología, la arqueología prehistórica y la historia cultural (Starr, 1901: V).

Tomando en cuenta sus publicaciones, es claro que una parte importante del trabajo de investigación de Starr se ubica en la antropología física, sobre todo a finales del siglo XIX y principios del XX; sin embargo, en los años posteriores realizó varios viajes a Europa, Asia y África, regresando a México varias veces. Quizá como consecuencia de dichas experiencias por distintas partes del mundo, Starr dejó de lado algunas posturas evolucionistas. Por lo menos eso sugiere su interés por el estudio de la educación indígena, como lo dejan ver varias de sus libretas de campo y algunas cartas entre él y personajes como Moisés Sáenz o Manuel Gamio en los años veinte.

\section{Frederick Starr, coleccionista}

Las conexiones que Starr fue estableciendo en México a lo largo del tiempo, tanto para adquirir piezas como para realizar sus investigaciones, fueron muchas. De hecho, es difícil separar unas de otras. El primero de sus múltiples viajes al país fue en el año 1894 y no tuvo fines científicos sino comerciales, cuando comenzó a comprar 
piezas para llevar a Estados Unidos. Entró en contacto con algunos coleccionistas de arte y empresarios mexicanos. Gracias a Starr, el Museo Walker de la Universidad de Chicago adquirió varias piezas arqueológicas de importantes colecciones (McVicker, 1986: 12). La colección de Antonio Peñafiel, por ejemplo, sumaba cerca de 2000 piezas e incluía ídolos, decoración para casas, cerámica, ornamentos de oro y moldes de bronce, además de algunas reproducciones de armas mexicanas elaboradas por el propio Peñafiel. Esa colección, producto de 20 años de trabajo, fue vendida por un total de 1700 dólares y se expuso en la feria de Tennessee de $1897^{1}$ (ver imagen 1).

Un aspecto muy significativo del interés de Starr por México se refiere a la participación del país en el centenario en Nashville, una feria internacional de grandes dimensiones que celebró los cien años del ingreso del estado de Tennessee a la Unión Americana. En ella se expusieron muchos de los recursos naturales de la nación, tanto minerales como agrícolas, además de numerosas piezas arqueológicas y de "folklore" que el propio Starr logró colectar en diferentes viajes y por distintas vías. México fue distinguido con un edificio especial en esa feria gracias al gran interés que tenían "los constructores del imperio del nuevo sur" en los recursos naturales de América Latina (Rydell, 1984: 92), en especial del país vecino, rico en petróleo y minerales.

William Powell, norteamericano y ministro de una misión bautista ubicada en la ciudad de Toluca, no sólo puso en contacto a Starr con varios coleccionistas, sino que también lo acompañó a algunos de sus recorridos científicos. En su correspondencia con Starr, Powell subraya en un par de ocasiones que estaba realizando su mejor esfuerzo para llevar a la feria de Nashville "las mejores cosas del Museo de Toluca." De hecho, este ministro bautista fue el comisionado especial para organizar la exhibición de México en la feria. A juicio de Powell, un aspecto central consistía en la exposición de una importante colección de más de 200 variedades de cactus. Incluso un periódico local llamó la atención sobre la exposición de plantas de Maguey "rodeadas por cuarenta artículos manufacturados con él" (citado en Rydell, 1984: 92). Se expusieron también varias clases de fibras y productos elaborados con fibra de maguey, artículos de piel y otras mercancías de muy diversas fábricas en México. ${ }^{3}$ La de Nashville fue una feria en la que México mostró a los norteamericanos las posibilidades de inversión que representaba el país.

\section{Frederick Starr, antropólogo físico}

En 1895, Starr viajó a México en búsqueda de esqueletos humanos (McVicker, 1986: 11). En esa ocasión, de manera casual tuvo un encuentro con un grupo indígena mixe en Mitla. Seis meses después pudo viajar, a caballo, desde Oaxaca a Guatemala, lo que le permitió adentrarse de manera más profunda en la región mixe y cruzar por el Istmo de Tehuantepec pasando por Chiapas. Ese recorrido reforzó en él su inquietud por estudiar la gran heterogeneidad de tipos físicos, idiomas y culturas de los indígenas mexicanos del "sur de México," que incluía, a su juicio, etnias de Jalisco, Michoacán, Guanajuato, Estado de México, Hidalgo, Guerrero, Tlaxcala, Puebla, Oaxaca, Yucatán y Chiapas (Starr, 1902, 1995).

Un 4 de enero de 1897, el Sr. Samuel T. Busey, norteamericano residente en Guanajuato, informaba a Frederick Starr sobre la posibilidad de conseguir moldes de huesos de la boca de indígenas tarascos. Samuel ofreció a Starr colectar el referido material; para ello, requería datos más precisos en cuanto a las características de las dentaduras que Starr buscaba. Busey estaba a punto de emprender un viaje hacia Zamora y Tangancícuaro, para después llegar a la región donde habitaban los indígenas tarascos. Solicitó a Starr que le hiciera llegar yeso y polvo de marfil, material necesario para elaborar los modelos. ${ }^{4}$

En su libro de 1902, Physical Characters of Indians of Southern Mexico, Starr afirma que, pese a las grandes diferencias "lingüísticas, arqueológicas y somáticas" entre los indígenas mexicanos, existía, a su juicio, un 
origen común (Starr, 1902: 53). En efecto, el antropólogo de la Universidad de Chicago era partidario del monogenismo. Para mostrar ese argumento, examinó un total de 23 "tribus" echando mano de la arqueología física. Su plan original de investigación consistía en realizar mediciones de 100 hombres y 25 mujeres de cada "tribu". Según Starr, ese número sería suficiente para arrojar resultados confiables. Dado que los "caracteres" de la raza eran más marcados en los hombres que en las mujeres, era necesario tener más medidas de los varones; por otro lado, Starr consideraba que medir a las mujeres era más complicado debido a sus miedos, terquedad y "estupidez". Las 14 medidas de cada cuerpo que Starr y su equipo realizaron eran las mismas que Franz Boas había utilizado en su investigación sobre las "tribus" de los Estados Unidos para la exposición mundial de Columbia en Chicago. En total, planeaba tomar las medidas de 2875 personas; sin embargo, al final lograron obtener datos de 2847 (Starr, 1902: 53).

Otro método de investigación, en palabras de Starr fue la fotografía. "De los 125 sujetos que pasaban por nuestras manos para las mediciones", afirma, "nosotros seleccionábamos aquellos que parecían presentar el tipo tribal para fotografiarlos". Existen más de 600 negativos de vidrio en el Museo Nacional Indígena del Instituto Smithsonian en Washington, Estados Unidos (Poole y Zamorano, 2011). A cada uno de los indígenas seleccionados se les tomaba una fotografía de frente y otra de perfil. Una selección de dichas imágenes fue publicada en un libro titulado Indians of Southern Mexico: An Ethnographic Album en el año 1902.

Para la elaboración de los bustos de yeso, Starr viajaba con un yesero que se encargaba de elaborar los moldes. El número total de bustos confeccionados por Starr es difícil de determinar con precisión, sobre todo porque generó varias series utilizando los mismos moldes. Después de un tiempo, el antropólogo vendió varias colecciones de bustos de yeso, con lo que financió parte de sus viajes e investigaciones en otras regiones del mundo. En el año 1902, el gobierno mexicano compró una serie de cien piezas para el Museo Nacional. En ese tiempo Starr buscaba encontrar compradores para otros tres juegos de cien bustos, todos ellos pintados de "forma adecuada." El precio era de 2500 dólares. En el año 1905 vendió una importante colección personal de objetos arqueológicos y etnológicos, incluidos 116 bustos de yeso. El Museo de Historia Natural de Chicago pagó a Starr la cantidad de nueve mil dólares (McVicker, 1986: 13). Con ese dinero viajó a Japón. Después siguió vendiendo bustos de "indígenas puros" al Museo Británico, al Museo de Etnografía de Berlín e incluso al Museo Nacional de Historia Natural de Paris. ${ }^{6}$ Por su lado, en el año 1909 autoridades de Italia recibieron con gusto la donación de 96 bustos de yeso, dado que el material era de gran interés para los etnólogos y antropólogos así como para el Museo Prehistórico de Roma. ${ }^{7}$

\section{Antropología y política}

El relato de los viajes de Frederick Starr por el sur de México incluye varios ejemplos de dificultades y resistencias que su equipo enfrentó a la hora de tratar de sacar los moldes de yeso, de tomar las medidas y de sacar las fotografías. Según Starr, un aspecto crucial para poder trabajar y obtener los datos fue mostrar "gran interés de hablar con la gente", así como "visitar sus casas" y establecer un contacto cercano con los habitantes (Starr, 1995: 11). Sin embargo, como el propio Starr lo señala unas páginas más adelante, en la práctica, más que "permanecer un largo tiempo en cada aldea" estableciendo "relaciones cordiales y personales con la gente," echó mano de sus contactos políticos, de las autoridades locales e incluso de la policía, permaneciendo en las localidades el tiempo mínimo indispensable para obtener los datos que le interesaban. El propio Starr afirma: "si se cuenta con la asistencia del gobierno, todo se puede lograr rápida y fácilmente" (Starr, 1995: 28). 
En efecto, para su trabajo como antropólogo físico, Starr contó con el apoyo del secretario de Fomento del gobierno de Porfirio Díaz, Manuel Fernández Leal, quien impulsó con entusiasmo la participación de México en varias exposiciones mundiales, como la de 1889 en Paris (Tenorio, 1998: 27). Fernández escribió varias cartas de recomendación a los gobernadores de los estados de Yucatán, Veracruz, Hidalgo, Morelos, Oaxaca, Guerrero, Zacatecas, Jalisco, Estado de México y Michoacán. Las cartas son prácticamente iguales. A manera de ejemplo se cita el documento dirigido a Francisco León, gobernador de Chiapas, fechado el 24 de noviembre de 1897:

Estimado Sr. y fino amigo:

Me permito introducir al conocimiento de Ud. al Sr. Profesor Frederick Starr, de la Universidad de Chicago, quien bondadosamente ayudó al gobierno en el arreglo de la exhibición de México en Nashville, en la exposición que acaba de celebrarse en dicha ciudad.

Viene a nuestro país el Sr. Starr con el objeto de hacer estudios científicos y yo, con tal motivo, suplico á Ud. que tenga la bondad de facilitarle esos estudios, prestándole, al efecto su genial atención, así como al Sr. Guillermo D. Powell que le acompaña, á quien la Secretaría a mi cargo á comisionado para procurar que los Gobiernos de los Estados y los productores del país concurran el año que entra á una exposición que ha de celebrarse en Omaha. ${ }^{8}$

En efecto, Starr logró que los gobernadores de los estados le otorgaran cartas de presentación (ver imagen 2). En ellas se expresan de distintas formas, tanto la confianza depositada en Starr, como la convicción de que sus investigaciones eran positivas para el "progreso" del país y de la nación. El 6 de febrero de 1901, el gobernador de Yucatán escribe al jefe político de Peto, Sr. Miguel Narváez y Pérez:
Estimado amigo:

Pasa á esa Villa el Sr. Profesor Don Federico Starr con el objeto de hacer algunos estudios científicos a cerca de las razas primitivas que han habitado esta Península; y al efecto piensa tomar fotografías de individuos de raza maya, obtener datos respecto á su estatura y demás circunstancias que puedan contribuir para una exacta clasificación étnica de ellos. Con tal motivo, se lo recomiendo para que me haga el favor de ayudarlo a todo lo que a Ud. le fuera posible para el buen éxito de sus trabajos; haciendo comprender a todos los que tengan que estar con él, que no lleva más objeto que el de adquirir nuevas noticias en interés de la ciencia á que está dedicado. ${ }^{9}$

Sin duda, es importante destacar el hecho de que los jefes políticos de aquel momento jugaron un papel importante en esta historia al extender cartas dirigidas a los presidentes municipales. El gobernador de Puebla escribe a Vicente Popoca, jefe político del distrito de Zacatlán:

Mi estimado Amigo:

Tengo el gusto de presentará Ud. al Señor Profesor FREDERICK STARR, de la Universidad de Chicago, que pasa á ese Distrito con el objeto de estudiar las razas indígenas que lo pueblan. La importancia que para nosotros tiene tal estudio, me anima á suplicar á Ud. atienda debidamente á dicho Señor, prestándole toda la ayuda que pueda necesitar y recomendándolo, de un modo especial, con las autoridades de los Municipios que visite. ${ }^{10}$

Por su lado, el gobernador de Oaxaca escribió al coronel Romualdo Zárate, jefe político de Nochixtlán (ver imagen 3):

Estimado compañero y amigo:

Pondrá la presente en tus manos el Señor don Federico Starr, Profesor de la Universidad de 
Chicago, que se dirige a ese Distrito a tu cargo, con objeto de hacer estudios sobre las razas indígenas; y mucho te recomiendo que de la manera más eficaz, te sirvas atenderlo y proporcionarle cuantos datos necesite, á fin de que no tenga dificultades para llevar a efecto sus importantes estudios."

Starr contó también con el apoyo de algunos curas católicos para llevar a cabo su trabajo, como lo señala el obispo Martín:

Sres. Curas de esta diócesis

El Sr. Dr. Federico Starr, Profesor de la Universidad de Chicago, viene á nuestro país con el fin de completar sus estudios antropológicos de la raza indígena, y trae consigo buenas recomendaciones del Episcopadonorteamericano. En tal virtud, yoá mi vez lo recomiendo á Uds. Para que se sirvan facilitarle la manera de realizar sus importantes investigaciones. ${ }^{12}$

\section{Epílogo}

Muchos de los documentos del archivo Frederick Starr ubicado en la colección especial de la Biblioteca Jospeh Regenstein de la Universidad de Chicago se refieren de distintas formas a la relación entre la antropología y la política en el México de fines del siglo XIX y principios del XX. Intelectuales, políticos e incluso algunos miembros destacados de la elite económica, estaban convencidos de la necesidad de civilizar a la población rural mexicana, en especial a la indígena. En esa tarea, la ciencia habría de ayudar. Varios de los papeles mencionados, como se ha mostrado, hacen referencia a los esfuerzos del gobierno mexicano por utilizar la antropología con fines políticos. En teoría, esa ciencia podría contribuir a la transformación de los indígenas en ciudadanos de un Estado moderno. Durante la Revolución, en la década de 1910, se dieron también esfuerzos en un sentido similar. Para concluir este documento introductorio, es sin duda importante destacar que Manuel Gamio, es decir, el indigenista más conocido e influyente de la primera mitad del siglo XX, reconoce en los trabajos de Frederick Starr un valor científico indudable. Gamio llegó incluso a afirmar que las obras escritas por Starr eran una referencia obligada en sus propias investigaciones.

\section{Notas}

${ }^{1}$ FSP, caja 1, f. 13, documento firmado por W. D. Powell, 20 de agosto de 1897. FSP hace referencia a Frederick Starr Papers, Archivos, Colección Especial ubicada en la Biblioteca Regenstein de la Universidad de Chicago.

${ }^{2}$ FSP, caja 1, f. 13, carta W.D. Powell a Frederick Starr, 1 de enero de 1897.

${ }^{3}$ FSP, caja 1, f. 13, carta W.D. Powell a Frederick Starr, 15 de enero de 1897.

${ }^{4}$ FSP, caja 1, f. 13, carta de Samuel T. Busey a Frederick Starr, 4 de junio de 1897.

${ }^{5}$ FSP, caja 1, f. 13, carta de Samuel T. Busey a Frederick Starr, 4 de junio de 1897.

${ }^{6}$ FSP, caja 3, f. 3, carta de Frederick Starr dirigida al cónsul de Italia en Chicago, 15 de marzo de 1909.

7 FSP, caja 3, f. 3, carta del Consulado de Italia en Chicago dirigida a Frederick Starr, 14 de julio de 1909

${ }^{8}$ FSP, caja 1, f. 13, carta de Manuel Fernández Lea dirigida al gobernador del estado de Chiapas, Francisco León, 24 de noviembre de 1897.

${ }^{9}$ FSP, caja 2, f. 4, Carta del Gobernador de Yucatán, Francisco Catón, dirigida al Jefe Político del Peto, Miguel Narváez y Pérez, 6 de febrero de 1901.

${ }^{10}$ FSP, caja 2, f. 3, Carta del Gobernador del Estado de Puebla dirigida al Jefe Político de Zacatlán, 3 de enero de 1900.

${ }^{11}$ FSP, caja 2, f. 3, Carta del Gobernador de Oaxaca, Martín González, dirigida al Jefe Político de Nochixtlán, Coronel Romualdo Zárate, 18 de enero de 1900.

${ }^{12}$ FSP, caja 2, f. 4, Carta del Obispo de Yucatán dirigida a los curas de la diócesis, 5 de febrero de 1901. 


\section{Bibliografía}

Baker, Lee (1998), From Savage to Negro, Anthropology and the construction of Race, 1896-1954, Los Angeles/Londres: University of California Press.

Dictionary of American Biography (1935), Nueva York: Charles Scribner's Sons, vol. XVIII.

Poole, Deborah y Gabriela Zamorano (eds.), en proceso de publicación, De frente al perfil: retratos fotográficos de Frederick Starr, México: El Colegio de Michoacán.

Rydell, Robert (1984), All the World's Fair, Chicago: The University of Chicago Press.

Starr, Frederick (1893), "Anthropology at the World`s Fair”, en Popular Science Monthly, vol. 43, núm. 5, pp. 610-621.

Starr, Frederick (1899a), American Indians, Boston: C.D, Heath \& Co., Publishers.

Starr, Frederick (1899b), Catalogue of a Collection of Objects Illustrating the Folklore of Mexico, Londres: Folklore Society and David Nutt.
Starr, Frederick (1900), Notes upon the Ethnography of Southern Mexico, edición del autor, Putman Memorial Publication Fund.

Starr, Frederick (1901), Some First Steps in Human Progress, Chicago: The Likeside Press.

Starr, Frederick (1902), Physical Characters of Indians of Southern Mexico, Chicago: The University of Chicago Press.

Starr, Frederick (1914), Mexico and the United States, A Story of Revolution, Intervention and War, Chicago: The Bible House.

Starr, Frederick (1995), En el México indio, México: CONACULTA.

Stocking, George (1979), Anthropology at Chicago: Tradition, Discipline, Department, Chicago: The University of Chicago.

Tenorio Trillo, Mauricio (1998), Artilugio de la nación moderna. México en las exposiciones universales, 1880-1930, México: FCE. 
B I L L O

Hexico City, August 20, 1897.

I hereby all and convey to Prot. Freterick Starr, of Clcago University, of chicago, Illinols, U. S. A. the entire collection of Hexican antiquitios, made by tho no,ed Mexican Arqueologist, Dr. Antonio Peñafiel during the past thixty years and consisting of ifols, houso lecorations pottery, gold ornanents, bronze castsy etc., beini some t\%o thousand pieces, all told; together with the reproduction of fextcan arms made by Dr. Antonio peirariel in the sum of SEVENCEEN HUNDRED DOLLARS ( $\$ 1700$ ) to be paid as follows: $\$ 500.00$ onsh; $\$ 500.00$ before November 1897 , the balance in two notes of $\$ 350.00$ each to be naid hy or before August 898 . The goods to be delivered in the Tennesseo C ntennisl, where they are now on exibition, and it is agrodd that all nodals and avards sliall bo the property of Proe. Starr.

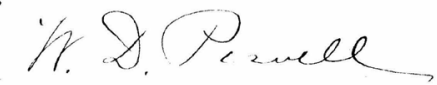

$$
\begin{aligned}
& c+1, \quad \text { " }
\end{aligned}
$$
CORRESPONDENCIA PARTICULAR
DEL GOBERMADOR DEL ESTADO DE VERACRUZ LLAVE.

Xalapa- Febrero $2 \%$ de 1900.-

Señor Lic. don

\section{J A C I N T O R O C H A,}

Jefe Político del cantón de Chicontepec

Bstinado antgo:-

TI Sr. Secretario de fomentc, en carta fecha 28 de niciembre último, me escribe 10 que sigue: "Tengo el gusto de presentar á Ua. por medio de estas líneas, al Sr. Profesor Frederick Starr, de la Universidad de chicago, quien recorre el país haciendo estudios sobre las razas indígenas que viven en él.- En vista del. interés que tiene para la Nación djcho estucio, me tomo la libertad de recomendar, muy eficazmente, á las finas atenciones de Ua. al expresaco $\mathrm{Sr}$. Starr, y me permito también suplicar á Ud. que tenga la bondad de proporcionarle cartas de recomendación para las autoridades locales deI Istado que dignamente Ud. gobierna, con el fin de que se faciliten al repetido Profesor sus importantes estudios."

Todo 10 cual. transcribo á Udi. recomendándole muy especialmente á su consideración al sr. Starr-portador de la presente.De Uå. afectísimo amizo y s.s.

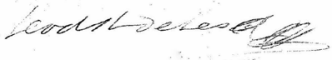


Correspontentia parifular

Gral. Narín González.

$$
\begin{aligned}
& \begin{array}{l}
\text { Oaxaca, Eneso } 18 \text { dej,900 } \\
\text { defe palitico }
\end{array} \\
& \text { Señordefe palitico } \\
& \text { Cetimado companten y anigo: } \\
& \text { Conacl Romaldo járate } \\
& \text { Pochixctán. }
\end{aligned}
$$

Pandrá lapucecute en ues moness, eldcuir Don Pedenico Ptam, Profeer de Rallini vereidad de letricago, que se dirije áese 9 istrito de tu cargo, counajeto de Praces cetudiato sobre las rasas indighas; y mucho te seco-s miendo que de ha inanera nuás eficais, te sinds atenderto y projurcionaste cuantes datus necerite, àfin de que no tenga difi--s cultades frara llevar à éfecto ens imperrtan-
tes eetudios.

Deecansando entueficaeia, gueedo a trygo afectisine companend yanigo.

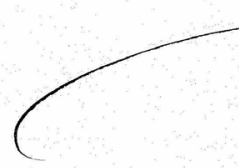

